\title{
Perancangan Alat Pemotong Kue Yangko dengan Metode Rasional
}

\author{
M. Khoirul Anwar, Jazuli, Ratih Setyaningrum \\ Teknik Industri, Fakultas Teknik, Universitas Dian Nuswantoro Semarang \\ Jl. Nakula 1 No.5-11, Semarang - Jawa Tengah, 50131 \\ e-mail: mkhoirul.4@gmail.com
}

\begin{abstract}
Yangko cake is a culinary area that is often used as souvenirs when visiting the city of Yogyakarta with a sticky texture, supple and soft. In yangko cake making, producers are faced with problems during the process of cutting the cake. It is necessary to have an effective cake cutter so that it can increase its productivity. From the results of research conducted by using rational methods, obtained the result that the cutting tool cake is designed by using sling cutting technology. The rational method consist of several stages: (1) clarifying objectives, (2) establish function, (3) setting requirement, (4) determining characteristic, (5) generating alternatives, (6) evaluating alternatives, dan (7) product improvements. From the results of experimental tools that have been done, obtained increased time efficiency and productivity cutting process as much as 60\%. In addition, the cuts using this tool also have better quality than before and reducing the number of defective products. In terms of use, this tool has a good enough resistance and is designed with the concept of ergonomics so it can be used with comfort.
\end{abstract}

Keywords: The Rational Method, Yangko Cake, Sling Cutting, Productivity

\begin{abstract}
Abstrak
Kue Yangko adalah kuliner daerah yang kerap dijadikan oleh-oleh ketika berkunjung ke Kota Yogyakarta dengan tekstur yang lengket, kenyal dan lembut. Dalam pembuatan kue yangko, produsen dihadapkan pada permasalahan saat proses pemotongan kue. Perlu adanya suatu alat pemotong kue yangko yang efektif sehingga dapat meningkatkan produktivitasnya. Dari hasil penelitian yang dilakukan dengan menggunakan metode rasional, didapatkan hasil bahwa alat pemotong kue yangko ini didesain dengan menggunakan teknologi sling cutting. Metode rasional terdiri dari beberapa tahapan: (1) clarifying objectives, (2) establish function, (3) setting requirement, (4) determining characteristic, (5) generating alternatives, (6) evaluating alternatives, dan (7) product improvements. Dari hasil uji coba alat yang telah dilakukan, didapatkan peningkatan efisiensi waktu dan produktivitas proses pemotongan sebanyak $60 \%$. Selain itu, hasil potongan dengan menggunakan alat ini juga memiliki kualitas yang lebih baik daripada sebelumnya sehingga mengurangi banyak produk yang defect. Dari sisi penggunaan, alat ini memiliki ketahanan yang cukup baik dan di desain dengan konsep ergonomi sehingga dapat digunakan dengan nyaman..
\end{abstract}

Kata kunci: Metode rasional, Kue yangko, Sling Cutting, Produktivitas

\section{Pendahuluan}

Yangko merupakan makanan atau jajanan khas Yogyakarta. Makanan ini dijual di berbagai toko oleh-oleh dengan harga yang bervariasi. Yangko memiliki bentuk yang khas dan belum berubah sejak pertama kali dibuat, yaitu kotak dengan tekstur yang lembut dan kenyal. Rasanya manis dan sedikit gurih, karena terdapat taburan tepung khas yang selalu melekat menjadi ciri khas kue Yangko ini. Kue ini memang mirip dengan kue moci, namun tekstur kue moci lebih lembek dan berisi kacang tanah. Seiring berjalannya waktu, kue yangko 
memiliki cita rasa yang lebih beraneka ragam, yakni beraneka rasa yang unik dan warnanya yang menyegarkan.

Proses pembuatan yangko yang dilakukan melalui beberapa tahapan, mulai dari tahap pembuatan isi yangko, tahap pembuatan adonan, tahap pengukusan, tahap pendinginan, tahap pemotongan, dan terakhir tahap pengemasan. Pada tahapan pemotongan merupakan salah satu tahapan yang cukup merepotkan pekerja dan memakan waktu cukup lama, yang mana dalam memotong satu loyang yangko $( \pm 8 \mathrm{~kg})$ diperlukan waktu kurang lebih 1 (satu) jam.

Untuk proses pemotongan yangko (Gambar 1) dilakukan dengan menggunakan sebuah pisau. Tekstur kue yangko yang lembek dan lengket merupakan kendala tersendiri dalam proses pemotongan manual. Pada setiap selesai satu kali pemotongan pisau akan diberi tepung supaya tidak lengket dengan yangko. Ukuran hasil pemotongan kue yangko adalah sekitar $3 \times 2 \mathrm{~cm}$. Berdasarkan hasil pengamatan juga diperoleh defect hasil pemotongan (berupa potongan yang tidak sesuai dan sisa-sisa potongan ditepi adonan) sekitar $\pm 6 \%$ dari satu adonan yang dipotong. Hal ini menjadikan efektifitas dan efisiensi proses pemotongan menjadi kurang maksimal. Defect tersebut meliputi bentuk potongan yang kurang sesuai dengan ukuran yang ditentukan dan sisa-sisa pemotongan pada tepian adonan yang berbentuk tidak beraturan (Gambar 2). Berikut adalah gambar dari proses pemotongan dan hasil pemotongan dari kue yangko di UKM Mulya Semarang:

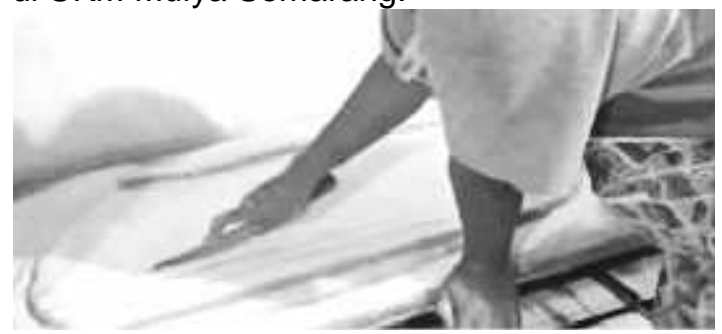

Gambar 1. Proses Pemotongan Kue Yangko di UKM Mulya

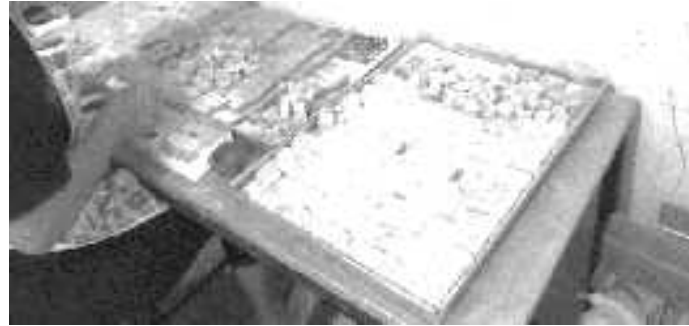

Gambar 2. Hasil Pemotongan Kue Yangko di UKM Mulya

Tujuan dari penelitian ini adalah untuk merancang alat pemotong yangko dengan metode Rasional untuk menghasilkan rancangan alat yang dapat mempermudah proses pemotongan serta meningkatkan produktivitas UKM pembuat kue yangko. Metode Rasional adalah salah satu metode perancangan produk yang menggunakan pendekatan sistematis. Metode Rasional banyak digunakan dalam perancangan produk karena dinilai memiliki tahapan yang jelas sehingga dapat memeberikan hasil rancangan dan produk akhir yang berkualitas [1]. Metode Rasional memiliki tujuan guna memperluas daerah penelitian untuk mencari solusi potensial atau menjadi fasilitator kelompok kerja dan kelompok pengambilan keputusan. Quality Function Deployment (QFD) merupakan salah satu tahapan dari metode rasional. Metode QFD adalah yang digunakan untuk menerjemahkan keinginan konsumen kedalam sebuah produk atau jasa [2]. Metode rasional telah digunakan oleh Rastaman [3] untuk mendesain mesin pemotong jerami serta Valentinus [4] untuk mendesain alat penyaring indigofera sebagai bahan pewarna alami tekstil. Berdasarkan latar belakang di atas, penulis bermaksud untuk merancang sebuah alat pemotong kue yangko yang efektif dan efisiens untuk meningkatkan produktivitas kue yangko pada UKM Mulya dengan metode Rasional

\section{Metode Penelitian}

Tahapan dalam melakukan penelitian ini dapat dilihat pada Gambar 3. Penelitian dimulai dengan melakukan survey awal, kemudian dilanjutkan dengan merumuskan masalah dan menetapkan tujuan. Setelah itu, kemudian dilakukan pengumpulan data baik dengan riset 
pustaka maupun riset penelitian. Pengolahan data dilakukan dengan menggunakan metode rasional yaitu: (1) clarifying objectives, (2) establish function, (3) setting requirement, (4) determining characteristic, (5) generating alternatives, (6) evaluating alternatives, dan (7) product improvements. Hasil dari penelitian ini adalah rancangan prototype dan implementasi pada UKM untuk kemudian dianalisis dan ditarik kesimpulan serta saran.

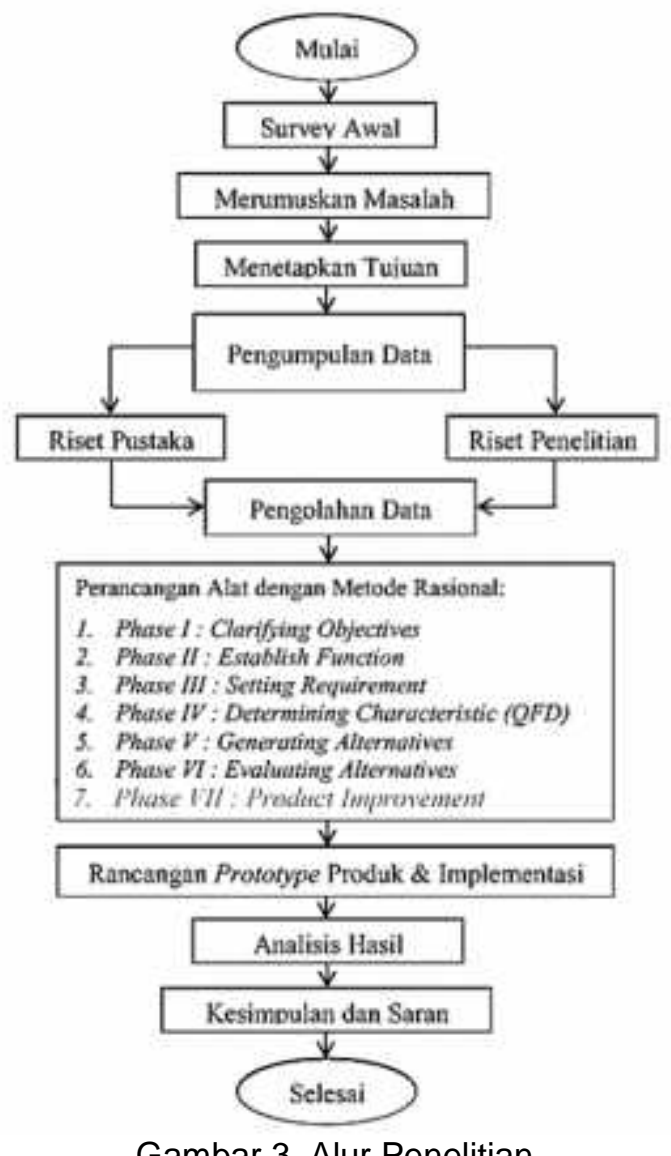

\section{Hasil dan Analisis}

Dari kuesioner yang disebarkan kepada responden dari beberapa UKM pembuat kue yangko di Semarang dan Yogyakarta diperoleh hasil sebagai berikut:

Tabel 1. Hasil Kuesioner Kondisi Pekerjaan

\begin{tabular}{|c|c|c|}
\hline Pertanyaan & Jawaban & Persentase \\
\hline Cara & Tradisional/manual & $100 \%$ \\
\cline { 2 - 3 } Pemotongan & Modern/alat baru & $0 \%$ \\
\hline \multirow{2}{*}{$\begin{array}{c}\text { Waktu } \\
\text { pemotongan }\end{array}$} & \pm 60 menit & $50 \%$ \\
\cline { 2 - 3 } & \pm 50 menit & $33 \%$ \\
\cline { 2 - 3 } Bentuk & \pm 40 menit & $17 \%$ \\
\hline potongan & Persegi & $33 \%$ \\
\hline \multirow{2}{*}{$\begin{array}{c}\text { Posisi kerja } \\
\text { Pemotongan }\end{array}$} & Persegi panjang & $67 \%$ \\
\cline { 2 - 3 } & Berdiri & $33 \%$ \\
\hline \multirow{2}{*}{$\begin{array}{c}\text { Keluhan } \\
\text { pekerja }\end{array}$} & Duduk & $67 \%$ \\
\cline { 2 - 3 } & Waktu lama & $0 \%$ \\
\cline { 2 - 3 } & Pisau lengket & $50 \%$ \\
\hline \multirow{2}{*}{$\begin{array}{c}\text { Alat yang } \\
\text { lebih baik }\end{array}$} & Ukuran tidak serasi & $33 \%$ \\
\cline { 2 - 3 } & Perlu & $67 \%$ \\
\cline { 2 - 3 } & Tidak perlu & $33 \%$ \\
\hline
\end{tabular}


Dari data kuesioner yang diperoleh tersebut kemudian dilakukan pengolahan data dengan menggunakan metode rasional.

\subsection{Clarifying object}

Pada tahapan clarifying objectives ini menggunakan metode objective tree. Tujuan dari penggunaan metode ini adalah untuk menjelaskan tujuan dan sub-tujuan dari perancangan dan juga menganalisis hubungan keduanya. Adapun objective tree untuk alat pemotong yangko ini dapat dilihat pada Gambar 4.

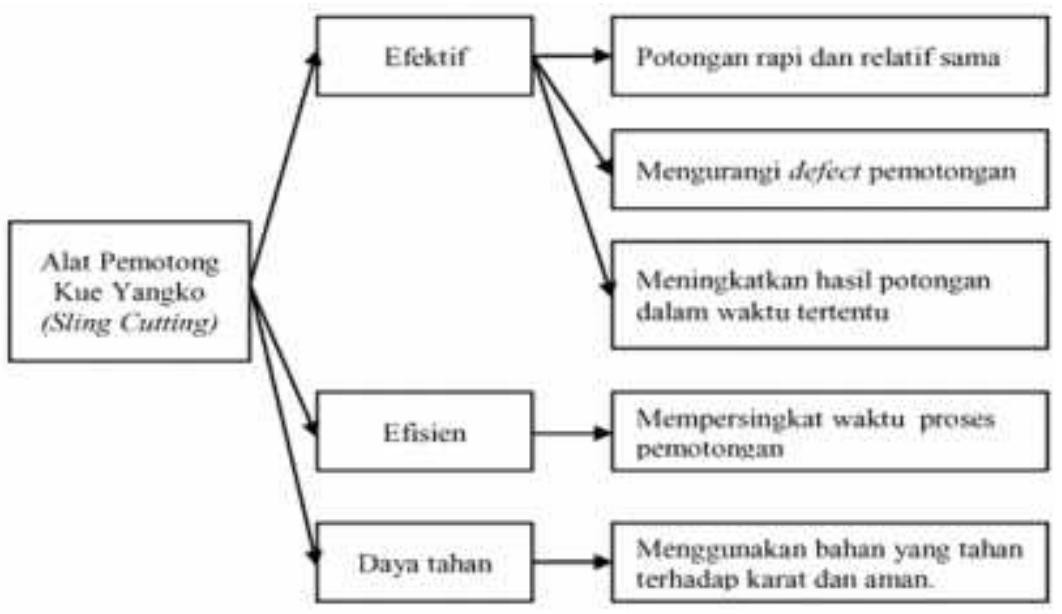

Gambar 4. Objective Tree Alat Pemotong Kue Yangko

\subsection{Establishing Function}

Pada tahapan establishing function ini menggunakan metode function analysis atau analisis fungsi yang bertujuan untuk menentukan fungsi-fungsi yang dibutuhkan dan batasan sistem dari perancangan alat pemotong kue yangko dengan teknik sling cutting (Gambar 5).

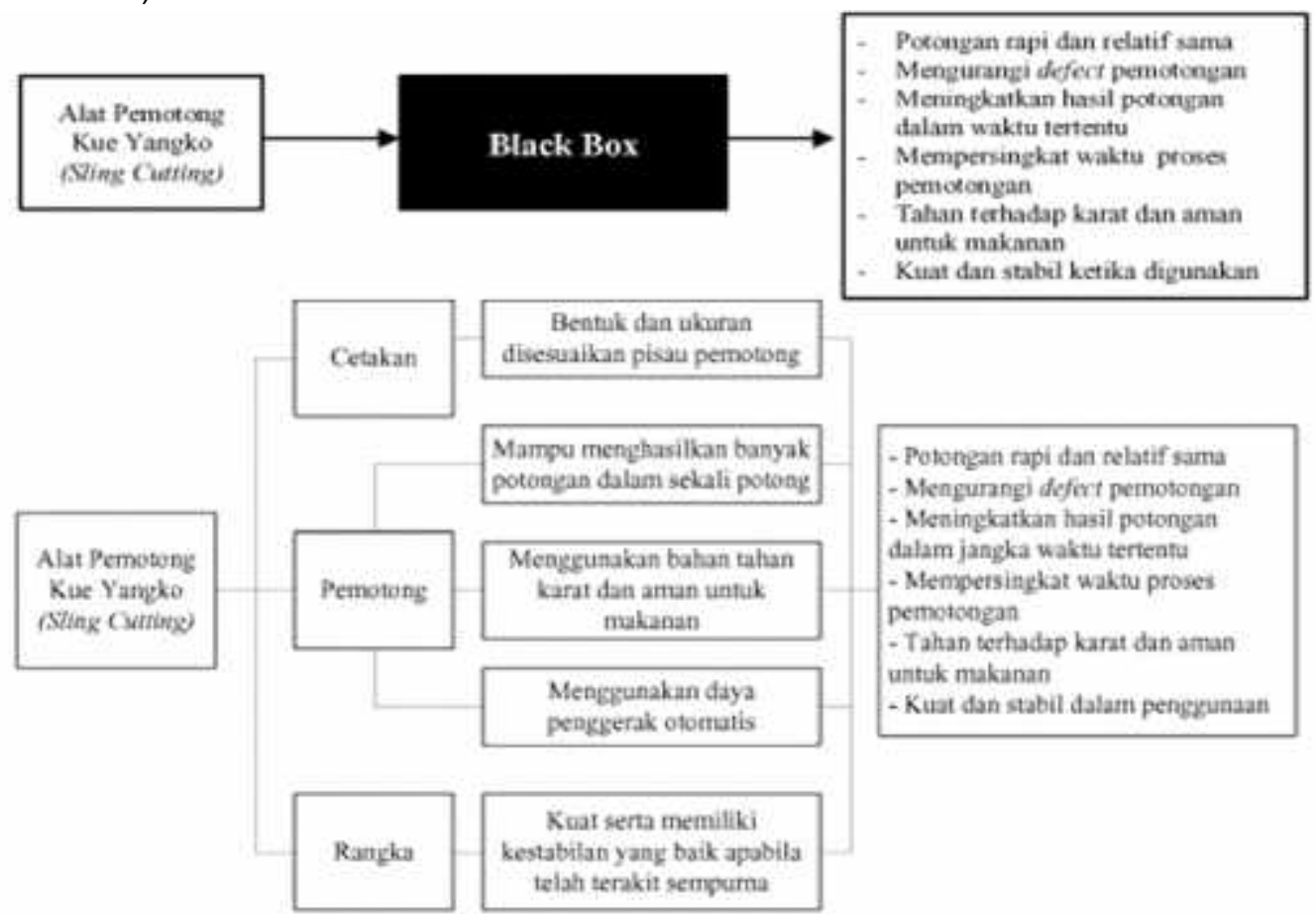

Gambar 5. Function Analysis Alat Pemotong Kue Yangko 


\subsection{Setting Requirements}

Dalam tahapan ini, metode yang digunakan adalah the performance specification atau spesifikasi performansi. Metode ini bertujuan untuk membuat spesifikasi yang akurat dari kebutuhan pelaksana suatu solusi perancangan alat. Adapun hasil analisis spesifikasi performansi untuk alatpemotong yangko ini dapat dilihat pada Tabel 2.

Tabel 2. Performance Spesification

\begin{tabular}{|c|c|}
\hline TUJUAN & KRITERIA \\
\hline \multirow{4}{*}{$\begin{array}{l}\text { Meningkatkan } \\
\text { efektifitas produksi } \\
\text { kue yangko }\end{array}$} & Jumlah output potongan meningkat dalam waktu tertentu \\
\hline & Bentuk potongan teratur dan relatif sama \\
\hline & Berkurangnya defect hasil \\
\hline & Praktis dalam penggunaan \\
\hline \multirow{4}{*}{$\begin{array}{l}\text { Meningkatkan } \\
\text { efisiensi produksi } \\
\text { kue yangko }\end{array}$} & Proses pemotongan yang mudah \\
\hline & Waktu pemotongan menjadi lebih \\
\hline & Mengurangi keluhan musculoskeletal pada pekerja bagian \\
\hline & Harga alat relatif terjangkau \\
\hline \multirow{3}{*}{$\begin{array}{l}\text { Dapat digunakan } \\
\text { dalam jangka waktu } \\
\text { yang lama }\end{array}$} & $\begin{array}{l}\text { Material kuat, tahan karat, dan aman untuk makanan pada } \\
\text { bagian pisau pemotong }\end{array}$ \\
\hline & Konstruksi yang kuat dan kokoh \\
\hline & Kemudahan pembersihan dan perawatan \\
\hline
\end{tabular}

\subsection{Determining Characteristics}

Pada tahapan ini metode yang digunakan adalah metode Quality Function Deployment (QFD). Tujuan dari tahapan ini adalah untuk dapat menetapkan target yang akan dicapai oleh karakteristik teknik produk sehingga dapat mewujudkan apa yang menjadi kebutuhan atau keinginan konsumen. QFD terdiri dari tiga tahap, seluruh kegiatan yang dilakukan pada masing-masing tahapan dapat diterapkan seperti layaknya suatu proyek, dengan terlebih dahulu dilakukan tahap perencanaan dan persiapan. Ketiga tahapan tersebut adalah:

a. Voice of Customer

Kebutuhan konsumen dapat diperoleh dari voice of customer yang dikumpulkan. Kebutuhan ini diungkapkan dalam bentuk pernyataan-pernyataan dari wawancara, kemudian diterjemahkan menjadi kebutuhan konsumen yang disusun berdasarkan tingkatan yang diinginkan dan dibutuhkan. Berdasarkan kuesioner yang telah disebarkan kepada 6 responden diperoleh beberapa poin yang menjadi pertimbangan kebutuhan. Kebutuhan tersebut diungkapkan dalam pernyataan yang disimbolkan dengan huruf $P$ disertai angka untuk mewakili urutan pernyataan.

Tabel 3. Daftar Kebutuhan Konsumen

\begin{tabular}{|c|l|}
\hline Pernyataan & Keterangan \\
\hline P1 & Jumlah output meningkat dalam jangka waktu tertentu \\
\hline P2 & Mata yang pisau yang tajam dan tidak lengket dengan kue \\
\hline P3 & Kemudahan dalam penggunaan alat \\
\hline P4 & Bahan alat yang kuat dan aman untuk makanan \\
\hline P5 & Kapasitas pemotongan yang besar \\
\hline P6 & Penyamaan ukuran semua hasil potong kue yangko \\
\hline P7 & $\begin{array}{l}\text { Alat penunjang otomatis sebagai opsi tambahan untuk lebih } \\
\text { mempercepat proses pemotongan }\end{array}$ \\
\hline P8 & Harga alat yang terjangkau \\
\hline
\end{tabular}

Perancangan Alat Pemotong Kue Yangko dengan Menggunakan Metode Rasional (Anwar) 
Untuk menentukan tingkat kepentingan konsumen (Tabel 4) dan kepuasan konsumen (Tabel 5), kuesioner menggunakan skala likert. Skala likert adalah cara pengukuran yang dilakukan dengan menghadapkan responden pada sebuah pertanyaan yang diberi skor 1 sampai 5 [5].

Tabel 4. Tingkat Kepentingan Konsumen

\begin{tabular}{|c|c|c|c|c|c|c|c|}
\hline P & $\mathbf{1}$ & $\mathbf{2}$ & $\mathbf{3}$ & $\mathbf{4}$ & $\mathbf{5}$ & Total & Nilai \\
P1 & 0 & 0 & 0 & 2 & 4 & 28 & 4.67 \\
\hline P2 & 0 & 0 & 0 & 3 & 3 & 27 & 4.50 \\
\hline P3 & 0 & 0 & 0 & 5 & 1 & 25 & 4.17 \\
\hline P4 & 0 & 0 & 1 & 0 & 5 & 28 & 4.67 \\
\hline P5 & 0 & 2 & 2 & 2 & 0 & 18 & 3.00 \\
\hline P6 & 0 & 0 & 1 & 4 & 1 & 24 & 4.00 \\
\hline P7 & 0 & 0 & 5 & 1 & 0 & 19 & 3.17 \\
\hline P8 & 0 & 0 & 1 & 5 & 0 & 23 & 3.83 \\
\hline
\end{tabular}

Tabel 5. Tingkat Kepuasan Konsumen

\begin{tabular}{|c|c|c|c|c|c|c|c|}
\hline P & $\mathbf{1}$ & $\mathbf{2}$ & $\mathbf{3}$ & $\mathbf{4}$ & $\mathbf{5}$ & Total & $\begin{array}{c}\text { Nilai } \\
\text { Kinaria }\end{array}$ \\
\hline P1 & 2 & 4 & 0 & 0 & 0 & 10 & 1.67 \\
\hline P2 & 2 & 4 & 0 & 0 & 0 & 10 & 1.67 \\
\hline P3 & 0 & 4 & 2 & 0 & 0 & 14 & 2.33 \\
\hline P4 & 0 & 0 & 4 & 2 & 0 & 20 & 3.33 \\
\hline P5 & 0 & 4 & 2 & 0 & 0 & 14 & 2.33 \\
\hline P6 & 3 & 3 & 0 & 0 & 0 & 9 & 1.50 \\
\hline P7 & 3 & 3 & 0 & 0 & 0 & 9 & 1.50 \\
\hline P8 & 0 & 0 & 4 & 2 & 0 & 20 & 3.33 \\
\hline
\end{tabular}

b. House Of Quality

Sebelum membuat House of Quality, sebelumnya perlu ditentukan terlebih dahulu daftar karakteristik teknis alat yang akan dibuat (Tabel 6).

Tabel 6. Daftar Karakteristik Teknis

\begin{tabular}{|l|l|l|}
\hline No. & Kebutuhan Konsumen & Karakteritik Teknis \\
\hline 1. & $\begin{array}{l}\text { Jumlah output meningkat dalam jangka } \\
\text { waktu tertentu }\end{array}$ & Sistem pemotongan sling cutting \\
\hline 2. & Mata pisau yang tajam dan tidak lengket & Pisau pemotong berupa kawat \\
\hline 3. & Kemudahan dalam penggunaan alat & Desain alat yang ergonomis \\
\hline 4. & $\begin{array}{l}\text { Bahan alat yang kuat dan aman untuk } \\
\text { makanan }\end{array}$ & $\begin{array}{l}\text { Jenis material kawat pemotong } \\
\text { stainless steel }\end{array}$ \\
\hline 5. & Kapasitas pemotongan & Ukuran pisau pemotong yang lebar \\
\hline 6. & $\begin{array}{l}\text { Penyamaan ukuran semua hasil potong } \\
\text { kue yangko }\end{array}$ & $\begin{array}{l}\text { Desain pisau pemotong yang } \\
\text { seragam }\end{array}$ \\
\hline 7. & $\begin{array}{l}\text { Alat penunjang otomatis untuk lebih } \\
\text { mempercepat proses pemotongan }\end{array}$ & Daya penggerak pneumatik \\
\hline 8. & Harga alat yang terjangkau & Jenis material rangka alat \\
\hline
\end{tabular}


Setelah proses mengidentifikasi kebutuhan konsumen hingga analisis daftar karakteristik teknis alat telah dilakukan, maka proses selanjutnya adalah menggabungkan langkah- langkah tersebut ke dalam House Of Quality (Gambar 6). Hubungan antara respon teknis dengan kebutuhan konsumen ditunjukkan dengan simbol yang melambangkan seberapa kuat hubungan antara keduanya (Tabel 7)

Tabel 7. Simbol Kekuatan Hubungan

\begin{tabular}{|l|l|l|}
\hline Simbol & Arti & Nilai \\
\hline & Tidak ada hubungan & 0 \\
\hline $\mathrm{A}$ & Kemungkinan ada hubungan & 1 \\
\hline $\mathbf{O}$ & Hubungan biasa-biasa saja & 3 \\
\hline $\mathbf{9}$ & Hubungan yang kuat & 9 \\
\hline
\end{tabular}

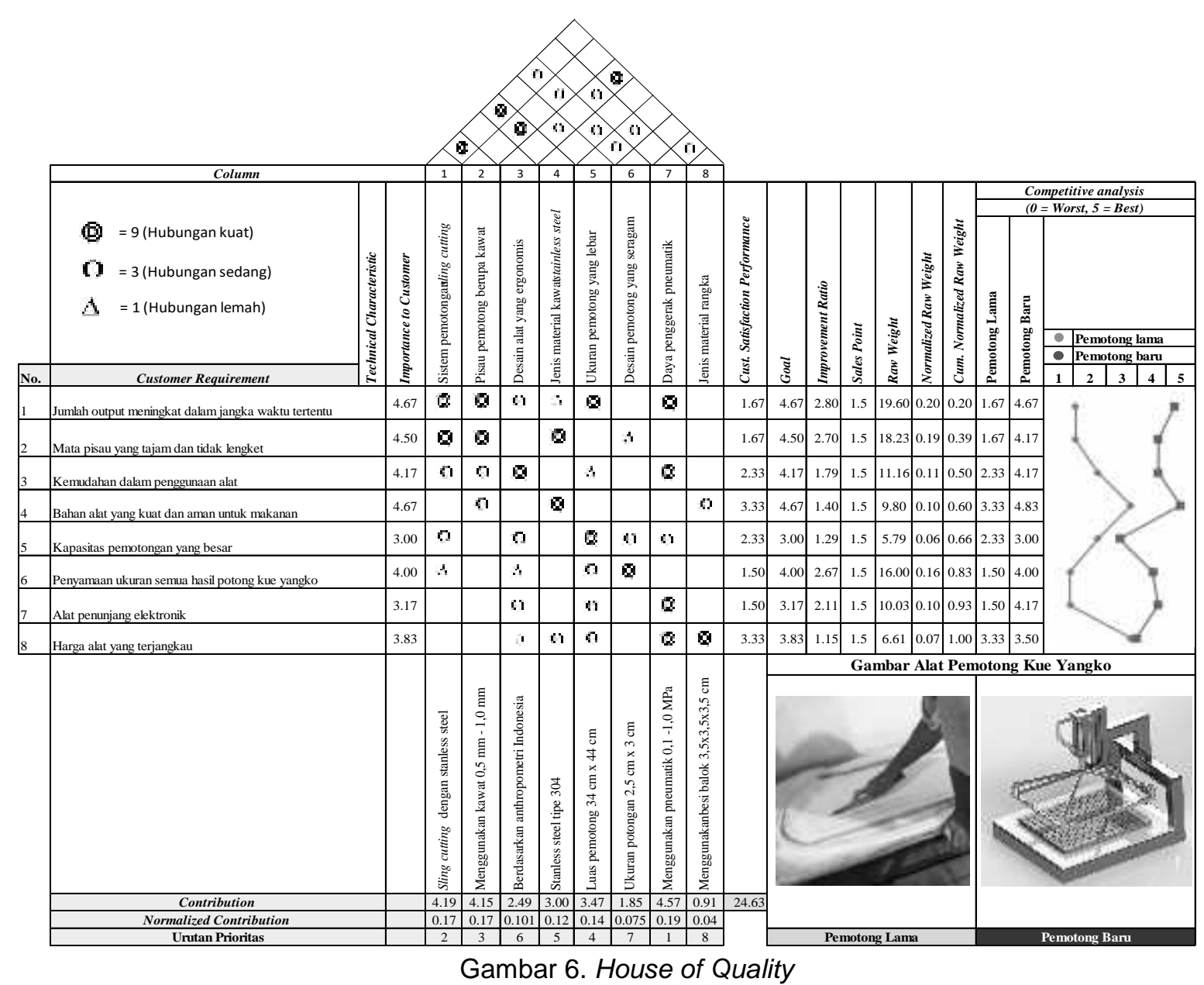

Berdasarkan perhitungan bobot hubungan antara kebutuhan konsumen dengan karakteristik teknis didapatkan nilai kontribusi dan urutan prioritas dari target spesifikasi. Berikut adalah 3 target spesifikasi dengan nilai kontribusi terbesar yang dapat dilihat pada Tabel 8

Tabel 8. Nilai Kontribusi Terbesar

\begin{tabular}{|l|l|l|}
\hline No. & Target Spesifikasi & Nilai \\
\hline 1. & Menggunakan pneumatik $0,1-1,0 \mathrm{MPa}$ & 4,57 \\
\hline 2. & Sling cutting dengan stainless steel & 4,19 \\
\hline 3. & Menggunakan benang kawat ukuran $0,5-1,0 \mathrm{~mm}$ & 4,15 \\
\hline
\end{tabular}


c. Analysis and Implementation

Analisa ergonomi dilakukan untuk mendapatkan ukuran sesuai data antropometri yang akan digunakan dalam perancangan alat pemotong kue yangko.

Tabel 9. Analisa Ergonomi Alat Sling Cutting

\begin{tabular}{|c|c|c|c|c|c|c|c|}
\hline Kegunaan & Dimensi & Persentil & Alasan Persentil & $\begin{array}{l}\text { Nilai } \\
\text { (cm) }\end{array}$ & $\begin{array}{l}\text { Nilai } \\
\text { Kelong } \\
\text {-garan }\end{array}$ & $\begin{array}{l}\text { Alasan } \\
\text { Kelong } \\
\text {-garan }\end{array}$ & $\begin{array}{c}\text { Ukuran } \\
\text { Rancangan } \\
\text { (cm) }\end{array}$ \\
\hline $\begin{array}{l}\text { Posisi ujung } \\
\text { penampang } \\
\text { alas potong }\end{array}$ & RTD & P5 & $\begin{array}{c}\text { Agar pengguna } \\
\text { dengan jangkauan } \\
\text { tangan pendek } \\
\text { dapat menjangkau }\end{array}$ & 69,22 & $+0,78$ & $\begin{array}{l}\text { Untuk } \\
\text { memper } \\
\text { mudah } \\
\text { perancan } \\
\text { gan alat }\end{array}$ & 70 \\
\hline $\begin{array}{l}\text { Posisi Tuas } \\
\text { pneumatik }\end{array}$ & RS & P5 & $\begin{array}{l}\text { Agar terjangkau } \\
\text { oleh pengguna } \\
\text { dengan rentang } \\
\text { tangan terkecil }\end{array}$ & 79,82 & $+0,18$ & $\begin{array}{l}\text { Untuk } \\
\text { memper } \\
\text { mudah } \\
\text { perancan } \\
\text { gan alat }\end{array}$ & 80 \\
\hline $\begin{array}{l}\text { Panjang } \\
\text { meja }\end{array}$ & RTS & P5 & $\begin{array}{l}\text { Agar ujung kanan } \\
\text { dan kiri meja } \\
\text { dapat terjangkau } \\
\text { oleh sebagian } \\
\text { besar dari } \\
\text { pengguna alat }\end{array}$ & 154,96 & $+0,04$ & $\begin{array}{l}\text { Untuk } \\
\text { memper } \\
\text { mudah } \\
\text { perancan } \\
\text { gan alat }\end{array}$ & 155 \\
\hline Tinggi meja & $\begin{array}{c}\text { TSD+TP } \\
0\end{array}$ & P50 & $\begin{array}{c}\text { Agar dapat } \\
\text { digunakan oleh } \\
\text { pengguna dari } \\
\text { dimensi rendah } \\
\text { hingga tinggi }\end{array}$ & $\begin{array}{r}23,9 \\
+38,96\end{array}$ & $+0,14$ & $\begin{array}{l}\text { Untuk } \\
\text { memper } \\
\text { mudah } \\
\text { perancan } \\
\text { gan alat }\end{array}$ & 63 \\
\hline
\end{tabular}

Keterangan:

$$
\begin{array}{ll}
\text { RTD } & =\text { Rentang Tangan ke Depan } \\
\text { RS } & =\text { Rentang Siku } \\
\text { RTS } & =\text { Rentang Tangan Samping } \\
\text { TSD } & =\text { Tinggi Siku Duduk } \\
\text { TPO } & =\text { Tinggi Popliteal }
\end{array}
$$

\subsection{Generating Alternatives}

Pada tahapan ini metode yang digunakan adalah dengan menggunakan morphology chart atau peta morfologi untuk membangkitkan range masing-masing solusi alternatif dari perancangan yang akan dilakukan dan juga melakukan perluasan terhadap solusi baru yang potensial. Morphology chart alat pemotong kue yangko adalah sebagai berikut: 
Tabel 10. Morphology Chart

\begin{tabular}{|c|c|c|c|c|}
\hline \multirow{2}{*}{ Atribut } & \multicolumn{3}{|c|}{ Alternatif } & \multirow{2}{*}{ Jumlah Alternatif } \\
\hline & 1 & 2 & 3 & \\
\hline $\begin{array}{l}\text { Sistem pemotongan } \\
\text { sling cutting }\end{array}$ & $\begin{array}{c}\text { Menggunakan } \\
\text { bahan stainless } \\
\text { steel }\end{array}$ & & & 1 \\
\hline $\begin{array}{c}\text { Pisau pemotong } \\
\text { berupa kawat }\end{array}$ & $\begin{array}{c}\text { Kawat dengan } \\
\text { diameter } 0,5-1,0 \\
\mathrm{~mm}\end{array}$ & & & 1 \\
\hline $\begin{array}{c}\text { Desain alat yang } \\
\text { ergonomis }\end{array}$ & $\begin{array}{c}\text { Sesuai dengan } \\
\text { analisa data } \\
\text { antropometri }\end{array}$ & & & 1 \\
\hline $\begin{array}{l}\text { Material kawat } \\
\text { pemotong stainless } \\
\text { steel }\end{array}$ & $\begin{array}{c}\text { Stainless steel tipe } \\
201\end{array}$ & \begin{tabular}{|c|} 
Stainless steel \\
tipe 304
\end{tabular} & $\begin{array}{c}\text { Stainless } \\
\text { steel tipe } 316\end{array}$ & 3 \\
\hline $\begin{array}{l}\text { Ukuran pisau } \\
\text { pemotong yang lebar }\end{array}$ & $40 \times 48 \mathrm{~cm}$ & & & 1 \\
\hline $\begin{array}{l}\text { Desain pisau } \\
\text { pemotong yang } \\
\text { seragam }\end{array}$ & $\begin{array}{c}\text { Dimensi hasil } \\
\text { potongan } 2,5 \times 2 \\
\mathrm{~cm}\end{array}$ & $\begin{array}{c}\text { Dimensi } \\
\text { hasil potongan }\end{array}$ & & 2 \\
\hline $\begin{array}{l}\text { Daya penggerak } \\
\text { pneumatic }\end{array}$ & $\begin{array}{l}\text { Menggunakan } \\
\text { pneumatik 0,1- }\end{array}$ & & & 1 \\
\hline $\begin{array}{l}\text { Jenis material rangka } \\
\text { alat }\end{array}$ & Besi & Alumunium & & 2 \\
\hline
\end{tabular}

Berdasarkan tabel di atas diperoleh kombinasi alternatif yaitu $1 \times 1 \times 1 \times 3 \times 1 \times 2 \times 1 \times 2=12$.

Sehingga kombinasi alternatif yang muncul adalah sebanyak 12 alternatif.

\subsection{Evaluating Alternatives}

a. Screening

Penghapusan beberapa alternatif berdasarkan penilaian terhadap karakter dari material yang diakomodasikan pada tahap generating alternatives.

Tabel 11. Penyaringan Alternatif

\begin{tabular}{|c|c|c|c|c|c|c|c|c|c|c|c|c|c|}
\hline \multirow[b]{2}{*}{ No. } & \multirow[b]{2}{*}{ Kriteria } & \multicolumn{12}{|c|}{ Alternatif } \\
\hline & & 1 & 2 & 3 & 4 & 5 & 6 & 7 & 8 & 9 & 10 & 11 & 12 \\
\hline 1. & $\begin{array}{l}\text { Jumlah output meningkat } \\
\text { dalam jangka waktu } \\
\text { tertentu }\end{array}$ & 0 & 0 & 0 & 0 & 0 & 0 & 0 & 0 & 0 & 0 & 0 & 0 \\
\hline 2. & $\begin{array}{l}\text { Mata pisau yang tajam dan } \\
\text { tidak lengket }\end{array}$ & 0 & 0 & 0 & 0 & 0 & 0 & 0 & 0 & 0 & 0 & 0 & 0 \\
\hline 3. & $\begin{array}{l}\text { Kemudahan dalam } \\
\text { penggunaan alat }\end{array}$ & 0 & 0 & 0 & 0 & 0 & 0 & 0 & 0 & 0 & 0 & 0 & 0 \\
\hline 4. & $\begin{array}{l}\text { Bahan alat yang kuat dan } \\
\text { aman untuk makanan }\end{array}$ & - & + & - & - & + & - & - & + & - & - & + & - \\
\hline 5. & $\begin{array}{l}\text { Kapasitas pemotongan } \\
\text { yang besar }\end{array}$ & 0 & 0 & 0 & 0 & 0 & 0 & 0 & 0 & 0 & 0 & 0 & 0 \\
\hline 6. & $\begin{array}{l}\text { Penyamaan ukuran semua } \\
\text { hasil potong kue yangko }\end{array}$ & 0 & + & 0 & + & 0 & + & 0 & + & 0 & + & 0 & + \\
\hline
\end{tabular}




\begin{tabular}{|c|c|c|c|c|c|c|c|c|c|c|c|c|c|}
\hline \multirow{2}{*}{ No. } & \multirow{2}{*}{ Kriteria } & \multicolumn{12}{|c|}{ Alternatif } \\
\hline & & 1 & 2 & 3 & 4 & 5 & 6 & 7 & 8 & 9 & 10 & 11 & 12 \\
\hline 7. & $\begin{array}{l}\text { Alat penunjang elektronik } \\
\text { untuk lebih mempercepat } \\
\text { proses pemotongan }\end{array}$ & + & + & + & + & + & + & + & + & + & + & + & + \\
\hline 8. & Harga alat yang terjangkau & + & + & + & + & + & + & 0 & 0 & 0 & 0 & 0 & 0 \\
\hline \multicolumn{2}{|c|}{ Total $(+)$} & 2 & 4 & 2 & 3 & 3 & 3 & 1 & 3 & 1 & 2 & 2 & 2 \\
\hline \multicolumn{2}{|c|}{ Total $(0)$} & 5 & 4 & 5 & 4 & 5 & 4 & 6 & 5 & 6 & 5 & 6 & 5 \\
\hline \multicolumn{2}{|c|}{ Total (-) } & 1 & 0 & 1 & 1 & 0 & 1 & 1 & 0 & 1 & 1 & 0 & 1 \\
\hline \multirow{2}{*}{\multicolumn{2}{|c|}{ Nilai Akhir }} & 1 & 4 & 1 & 2 & 3 & 2 & 0 & 3 & 0 & 1 & 2 & 1 \\
\hline & & $x$ & $\sqrt{ }$ & $\mathrm{x}$ & $\sqrt{ }$ & $\sqrt{ }$ & $\sqrt{ }$ & $x$ & $\sqrt{ }$ & $x$ & $x$ & $\sqrt{ }$ & $x$ \\
\hline
\end{tabular}

b. Pembobotan

Tahapan selanjutnya adalah pembobotan, yang mana dalam pembobotan ini berdasarkan pada nilai hasil preferensi responden terhadap masing-masing kriteria pada kuesioner.

Tabel 12. Pembobotan Objektif Setiap Kriteria

\begin{tabular}{|c|l|c|c|}
\hline No. & Kriteria & Raw & Normalized \\
\hline 1. & Jumlah output meningkat & 19.60 & 0.20 \\
\hline 2. & Mata pisau yang tajam & 18.23 & 0.19 \\
\hline 3. & Kemudahan dalam & 11.16 & 0.11 \\
\hline 4. & Bahan alat yang kuat dan & 9.80 & 0.10 \\
\hline 5. & Kapasitas pemotongan & 5.79 & 0.06 \\
\hline 6. & Penyamaan ukuran & 16.00 & 0.16 \\
\hline 7. & $\begin{array}{l}\text { Alat penunjang elektronik untuk lebih } \\
\text { mempercepat proses pemotongan }\end{array}$ & 10.03 & 0.10 \\
\hline 8. & Harga alat yang & 6.61 & 0.07 \\
\hline Total & & 97.21 & 1.00 \\
\hline
\end{tabular}

c. Penilaian

Pada tahap penilaian ini dilakukan pemberian nilai terhadap masing-masing kriteria untuk memilih salah satu dari alternatif yang telah disaring. Nilai (skor) yang diperoleh untuk masing-masing kriteria merupakan hasil perkalian antara nilai bobot dan nilai rating. Penilaian rating dilakukan dengan menggunakan skala likert 5 titik yaitu dari 0 sampai 4.

Tabel 13. Hasil Penilaian Alternatif

\begin{tabular}{|c|c|c|c|c|c|c|c|c|c|c|c|c|c|}
\hline \multirow{3}{*}{ Kriteria } & \multirow{3}{*}{ Bobot } & \multicolumn{12}{|c|}{ Alternatif } \\
\hline & & \multicolumn{2}{|c|}{2} & \multicolumn{2}{|c|}{4} & \multicolumn{2}{|c|}{5} & \multicolumn{2}{|c|}{6} & \multicolumn{2}{|c|}{8} & \multicolumn{2}{|c|}{11} \\
\hline & & Rating & Skor & Rating & Skor & Rating & Skor & Rating & Skor & Rating & Skor & Rating & Skor \\
\hline $\begin{array}{l}\text { Mata pisau } \\
\text { yang tajam dan } \\
\text { tidak lengket }\end{array}$ & 0.19 & 4 & 0.75 & 4 & 0.75 & 4 & 0.75 & 4 & 0.75 & 4 & 0.75 & 4 & 0.75 \\
\hline $\begin{array}{l}\text { Kemudahan } \\
\text { dalam } \\
\text { penggunaan } \\
\text { alat }\end{array}$ & 0.11 & 4 & 0.46 & 4 & 0.46 & 4 & 0.46 & 4 & 0.46 & 4 & 0.46 & 4 & 0.46 \\
\hline $\begin{array}{l}\text { Bahan alat } \\
\text { yang kuat dan } \\
\text { aman untuk } \\
\text { makanan }\end{array}$ & 0.10 & 4 & 0.40 & 2 & 0.20 & 4 & 0.40 & 3 & 0.30 & 4 & 0.40 & 4 & 0.40 \\
\hline
\end{tabular}




\begin{tabular}{|c|c|c|c|c|c|c|c|c|c|c|c|c|c|}
\hline \multirow{3}{*}{ Kriteria } & \multirow{3}{*}{ Bobot } & \multicolumn{12}{|c|}{ Alternatif } \\
\hline & & \multicolumn{2}{|c|}{2} & \multicolumn{2}{|c|}{4} & \multicolumn{2}{|c|}{5} & \multicolumn{2}{|c|}{6} & \multicolumn{2}{|c|}{8} & \multicolumn{2}{|c|}{11} \\
\hline & & Rating & Skor & Rating & Skor & Rating & Skor & Rating & Skor & Rating & Skor & Rating & Skor \\
\hline $\begin{array}{l}\text { Penyamaan } \\
\text { ukuran semua } \\
\text { hasil potong } \\
\text { kue yangko }\end{array}$ & 0.16 & 4 & 0.66 & 4 & 0.66 & 3 & 0.49 & 4 & 0.66 & 4 & 0.66 & 3 & 0.49 \\
\hline $\begin{array}{l}\text { Alat penunjang } \\
\text { elektronik } \\
\text { untuk lebih } \\
\text { mempercepat } \\
\text { proses } \\
\text { pemotongan }\end{array}$ & 0.10 & 3 & 0.31 & 3 & 0.31 & 3 & 0.31 & 3 & 0.31 & 3 & 0.31 & 3 & 0.31 \\
\hline $\begin{array}{l}\text { Harga alat } \\
\text { yang } \\
\text { terjangkau }\end{array}$ & 0.07 & 3 & 0.20 & 3 & 0.20 & 3 & 0.20 & 3 & 0.20 & 2 & 0.14 & 2 & 0.14 \\
\hline \multicolumn{2}{|c|}{ Total Nilai Akhir } & \multicolumn{2}{|c|}{3,77} & \multicolumn{2}{|c|}{3,57} & \multicolumn{2}{|c|}{3,60} & \multicolumn{2}{|c|}{3,67} & \multicolumn{2}{|c|}{3,70} & \multicolumn{2}{|c|}{3,54} \\
\hline \multicolumn{2}{|c|}{ Lanjutkan? } & \multicolumn{2}{|c|}{$\sqrt{ }$} & \multicolumn{2}{|c|}{$x$} & \multicolumn{2}{|c|}{$x$} & \multicolumn{2}{|c|}{$\mathrm{x}$} & \multicolumn{2}{|c|}{$x$} & \multicolumn{2}{|c|}{$x$} \\
\hline
\end{tabular}

Berdasarkan hasil penilaian alternatif, terpilih alternatif terbaik yaitu pada alternatif ke 2 dengan skor 3,77 . Hasil tersebut akan digunakan sebagai acuan untuk pembuatan rancangan alat pemotong kue yangko.

Tabel 14. Alternatif Terpilih

\begin{tabular}{|c|c|c|}
\hline No. & Atribut & Spesifikasi \\
\hline 1. & Sistem pemotongan sling cutting & Menggunakan bahan stainless steel \\
\hline 2. & Pisau pemotong berupa kawat & Kawat dengan diameter $0,5-1,0 \mathrm{~mm}$ \\
\hline 3. & Desain alat yang ergonomis & Sesuai dengan analisa \\
\hline 4. & Jenis material kawat pemotong stainless & Stainless steel tipe 304 \\
\hline 5. & Ukuran pisau pemotong yang lebar & $40 \times 48 \mathrm{~cm}$ \\
\hline 6. & Desain pisau pemotong yang seragam & Dimensi hasil potongan $2,5 \times 3 \mathrm{~cm}$ \\
\hline 7. & Daya penggerak pneumatik & Menggunakan pneumatik \\
\hline 8. & Jenis material rangka alat & Besi \\
\hline
\end{tabular}

\subsection{Product Improvement}

a. Pembuatan Desain Alat

Adapun desain alat berupa gambar 3 dimensi dapat dilihat pada Gambar 7.

Sedangkan untuk Gambar kerja dapat dilihat pada Gambar 8.
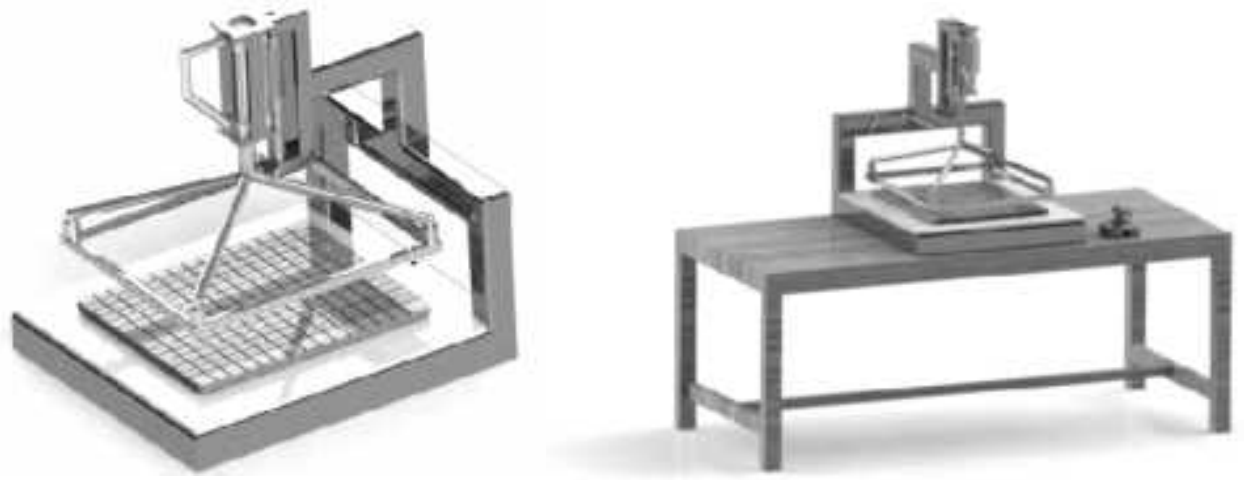

Gambar 7. Desain 3D Alat Pemotong Yangko 


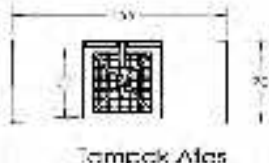

7ompek. Ates
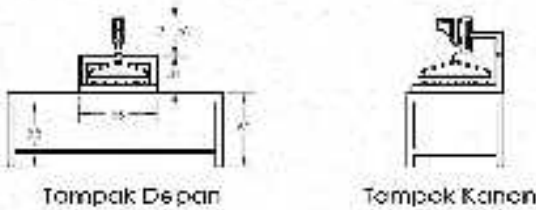

Gambar 8. Gambar Kerja Alat Pemotong Yangko

b. Realisasi Alat

Realisasi alat dapat dilihat pada Gambar 9.

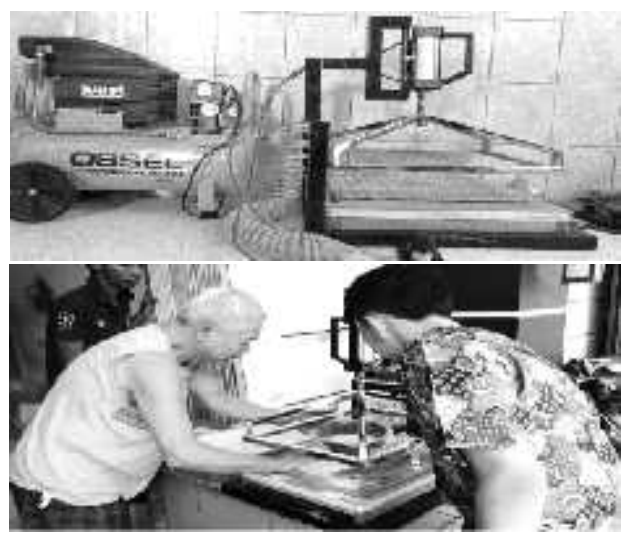

Gambar 9. Alat yang Telah Dibuat

c. Uji Coba Alat

alat pemotong yangko yang telah selesai dibuat diuji cobakan/diimplementasikan dalam tiga tahapan yang dapat dilihat pada Tabel 15.

Tabel 15. Tahapan Uji Coba Alat

\begin{tabular}{|l|l|l|}
\hline Tahapan & Hasil & Keterangan \\
\hline Uji Coba 1 & $\begin{array}{l}\text { Alat potong (sling) belum bisa } \\
\text { menembus seluruh bagian kue } \\
\text { yangko dengan sempurna. }\end{array}$ & $\begin{array}{l}\text { Kawat sling kurang kencang } \\
\text { sehingga pada proses } \\
\text { pemotongan kawat menjadi } \\
\text { kendor. }\end{array}$ \\
\hline Uji Coba 2 & $\begin{array}{l}\text { Alat sudah dapat menembus seluruh } \\
\text { bagian kue yangko namun setelah } \\
\text { kawat sling menembus kue, } \\
\text { potongan kue menempel kembali } \\
\text { satu sama lain karena terlalu lengket }\end{array}$ & $\begin{array}{l}\text { Kawat sling terlalu kecil dan } \\
\text { tekstur kue yang sangat lengket } \\
\text { sehingga mudah menempel } \\
\text { kembali meski sudah terpotong }\end{array}$ \\
\hline Uji Coba 3 & $\begin{array}{l}\text { Alat sudah dapat memotong seluruh } \\
\text { bagian kue yangko dan } \\
\text { menghasilkan potongan yang rapi } \\
\text { dengan adonan 3 kg dalam waktu 15 } \\
\text { menit }\end{array}$ & $\begin{array}{l}\text { Alat sudah berjalan dengan baik } \\
\text { dan menghasilkan potongan yang } \\
\text { rapi dan seragam }\end{array}$ \\
\hline \multicolumn{2}{|l|}{} \\
\hline
\end{tabular}


Setelah melakukan uji coba alat, diperoleh beberapa hasil pengukuran dari proses pemotongan kue yangko. Untuk parameter keberhasilan dari sebuah perancangan alat pemotong adalah ada tiga yaitu, tingkat kerusakan hasil, tingkat kapasitas efektif, dan tingkat efisiensi pemotongan. Adapun rumusnya adalah:

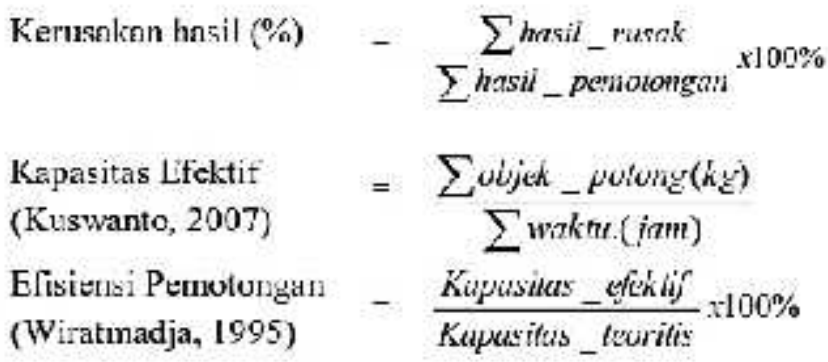

Tabel 16. Hasil Pengukuran Proses Pemotongan Kue Yangko

\begin{tabular}{|l|c|c|}
\hline Parameter & Manual & Sling \\
\hline Input (kg) & 3 & 3 \\
\hline Waktu potong (menit) & 25 & 15 \\
\hline Kerapian & baik & Baik \\
\hline Keseragaman & sedang & Baik \\
\hline Hasil potong & \pm 256 & 256 \\
\hline Kerusakan $(\mathrm{kg})$ & 0.2 & 0.1 \\
\hline
\end{tabular}

Dari Tabel 16, hasil pengukuran dapat dihitung perbandingan nilai efektifitas dan efisiensi dari hasil pemotongan seperti yang ada pada tabel di bawah ini:

Tabel 17. Efektifitas dan Efisiensi

\begin{tabular}{|l|c|c|}
\hline Parameter & Manual & Sling Cutting \\
\hline Kerusakan (\%) & 6.67 & 3.33 \\
\hline Kapasitas efektif (kg/jam) & 7.20 & 12.00 \\
\hline Kapasitas teoritis (kg/jam) & 15 & 15 \\
\hline Efisiensi (\%) & 48.00 & 80.00 \\
\hline
\end{tabular}

Alat sling cutting yang dibuat telah menunjukkan kinerja yang efektif, yaitu dapat membawa hasil yang lebih baik dari sebelumnya dan berhasil guna sesuai harapan (Tabel 18). Selain itu alat pemotong kue yangko sling cutting yang dibuat juga memiliki kemampuan menjalankan fungsinya dengan baik dan tepat (dengan lebih menghemat waktu, tenaga, dan biaya), sehingga terbilang lebih efisien.

Tabel 18. Perbandingan Pemotongan Manual dengan Sling Cutting

\begin{tabular}{|l|l|l|}
\hline Variabel & Manual & Sling Cutting \\
\hline Fungsional & $\begin{array}{l}\text { Untuk memotong } 3 \mathrm{~kg} \text { adonan kue } \\
\text { yangko memerlukan waktu kurang } \\
\text { lebih 25 menit. }\end{array}$ & $\begin{array}{l}\text { Memerlukan waktu } \\
\text { sekitar 15 menit untuk memotong } \\
3 \mathrm{~kg} \text { adonan, adanya peningkatan }\end{array}$ \\
\hline Ergonomi & $\begin{array}{l}\text { Kurang ergonomis karena posisi } \\
\text { kerja dalam keadaan sedikit } \\
\text { membungkuk dan melelahkan. }\end{array}$ & $\begin{array}{l}\text { Lebih ergonomis karena dimensi } \\
\text { alat yang disesuaikan dengan } \\
\text { data antropometri. }\end{array}$ \\
\hline Kemudahan & $\begin{array}{l}\text { Mudah namun cukup memerlukan } \\
\text { banyak waktu dan tenaga. }\end{array}$ & $\begin{array}{l}\text { Mudah digunakan, dapat } \\
\text { menghemat waktu dan tenaga. }\end{array}$ \\
\hline
\end{tabular}




\begin{tabular}{|l|l|l|}
\hline Variabel & Manual & Sling Cutting \\
\hline Daya Tahan & $\begin{array}{l}\text { Bahan baku yang kuat dan tahan } \\
\text { lama. }\end{array}$ & $\begin{array}{l}\text { Bahan baku kuat, aman untuk } \\
\text { makanan, dan alat stabil saat } \\
\text { digunakan. }\end{array}$ \\
\hline Harga & Sangat terjangkau & Cukup terjangkau \\
\hline
\end{tabular}

\section{Kesimpulan}

Berdasarkan hasil pembahasan yang telah dilakukan pada perancangan alat pemotong kue yangko dengan teknik sling cutting dapat ditarik kesimpulan bahwa dari perancangan alat pemotong kue yangko dengan teknik sling cutting menggunakan metode rasional didapatkan hasil bahwa produktivitas proses pemotongan kue yangko mengalami peningkatan. Hal tersebut dapat dilihat dari beberapa faktor, diantaranya waktu pada pemotongan manual adalah \pm 25 menit sedangkan dengan alat sling cutting lebih cepat menjadi \pm 15 menit. Tingkat deffect pada pemotongan manual sebesar $\pm 6,6 \%$ sedangkan dengan menggunakan alat menjadi $\pm 3,3 \%$. Kapasitas efektif pada proses pemotongan manual adalah $7,2 \mathrm{~kg}$ sedangkan dengan alat meningkat menjadi $12 \mathrm{~kg}$ per jam. Kemudian tingkat efisiensi dari pemotongan manual adalah $48 \%$ sedangkan setelah menggunakan alat meningkat menjadi $80 \%$. Alat pemotong sling cutting ini didesain dengan mempertimbangkan aspek ergonomis sehingga dapat memberikan kenyamanan bagi pekerja dalam proses pemotongan kue yangko. Material yang digunakan dalam pembuatan alat ini adalah material yang aman, khususnya pada bagian alat yang bersentuhan langsung dengan kue yangko terbuat dari material stainless steel tipe 304 yang aman untuk makanan.

\section{Referensi}

[1] Cross, N. 1994. Engineering Design Methods Strategies for Product Design. John Wiley and Sons Ltd: United Kingdom.

[2] Cohen, Lou. 2010. Quality Function Deployment, How to Make QFD Work For You. Addison- Wesley Publishing Company: New York.

[3] Rastaman, Wian dkk. 2010. Rancang Bangun dan Mesin Pemotong Jerami. Skripsi. Universitas Diponegoro: Semarang.

[4] Valentinus, Gabriel. 2016. Perancangan Alat Penyaring Endapan Indigofera Sebagai Bahan Pewarna Alami Tekstil untuk Meningkatkan Produktivitas Menggunakan Metode Rasional. Skripsi. Universitas Dian Nuswantoro: Semarang.

[5] Singarimbun, Masri. 1995. Metode Penelitian Survei. LP3S: Jakarta. 